\title{
Utilização de ferramentas tecnológicas como instrumento de aprendizagem para o investidor do mercado de ações
}

Edgard Devanir Amoroso'

\section{Resumo}

O mercado financeiro apresenta vários desafios para os operadores e investidores. Ele é composto cada vez mais de dispositivos e mecanismos complexos que, muitas vezes, desafiam o comportamento e o conhecimento humano. A experiência e o aprendizado são ferramentas importantes para balizar investimentos no mercado de capitais. Parte desse mercado trata sobre o mercado de ações, em que segundos podem representar perdas significativas a seus investidores. Muitas pesquisas estão sendo realizadas utilizando modelos e ferramentas tecnológicas, envolvendo, principalmente, a mineração de dados para agregar conhecimentos aos envolvidos nesse mercado. O presente artigo busca apresentar algumas dessas pesquisas, servindo como norte aos profissionais que lidam com o mercado de ações e permitindo uma maior visibilidade a todos os interessados neste assunto.

Palavras-chave: Gestão do conhecimento. Mercado de ações. Ferramentas tecnológicas. Data Mining. Inteligência artificial.

1 Professor Universitário de graduação na Universidade Católica de Brasilia nas disciplinas de Banco de Dados, Fundamentos de Banco de Dados e Sistemas Operacionais, professor do curso de pós-graduação em Governança de TI do UniCEUB na disciplina de Segurança da Informação e professor e tutor de pós-graduação em Gerência de Projetos na Anhanguera Educacional nas disciplinas de Gestão Estratégica da Informação, Gestão de Aquisição e Contratos e Tópicos em Desenvolvimento de Software. Possuí graduação em Processamento de Dados, Pós-graduação em Desenvolvimento, Qualidade e Segurança de Aplicações para Internet e Mestrado em Gestão do Conhecimento e Tecnologia da Informação. 


\section{Introdução}

Em uma economia globalizada, impulsionada por informações oriundas de múltiplas fontes, às vezes positivas, às vezes negativas, a aplicação de recursos financeiros é um verdadeiro quebra-cabeças para os investidores. Todo investidor, no momento de efetivá-la, pensa em três aspectos básicos: retorno, prazo e segurança do meio em que está aplicando. Nesse contexto, a rentabilidade está diretamente relacionada ao grau de risco que a aplicação representa. Quanto maior a probabilidade de gerar grandes rendimentos em curto, médio ou longo prazo, maior o risco que o investidor está correndo.

Existem tipos de aplicações com rentabilidade menor e com baixíssimo risco envolvido. É o caso de aplicações em caderneta de poupança ou fundos de investimentos lastreados por meio de títulos do governo federal. Outras, entretanto, têm alto risco envolvido, tais como fundos de investimentos garantidos por ações de empresas, comercializadas por meio da bolsa de valores, ou das próprias ações compradas diretamente de consórcio de investidores ou mesmo por investidores individuais. Ao investidor, cabe a definição do grau de risco que quer correr, levando em consideração a rentabilidade pretendida para o seu capital e o seu conhecimento sobre os mercados.

Para auxiliar os investidores a enfrentarem os problemas de volatilidade e insegurança do mercado financeiro, incluindo o de ações, tem ocorrido grande interesse por parte de pesquisadores na análise do comportamento desse mercado e de seus atores, agregando a essa pesquisa a gestão do conhecimento e informações oriundas de ferramentas tecnológicas alimentadas com dados históricos desse mercado.

\section{Revisão bibliográfica}

\subsection{Gestão do conhecimento}

Segundo Drucker (1993), “[...] os grandes ganhos de produtividade, daqui para frente, advirão das melhorias na gestão do conhecimento.” Embora o contexto 
da Gestão do Conhecimento (GC) vivenciado naquela época estivesse direcionado prioritariamente para a mudança na forma de gestão nas empresas, já se pregava sua utilização como forma de obtenção, entre diversas outras possibilidades, de melhores resultados financeiros (CAVALCANTI, 2000).

A GC vem se tornando uma preocupação cada vez maior no dia a dia de todos em um ambiente onde as mudanças são constantes e a competitividade para as organizações é uma palavra que pode significar sua sobrevivência.

Segundo Nonaka e Takeuchi (1997), o conhecimento pode ser definido como explícito ou tácito. Conhecimento explícito é aquele que indivíduos conseguem comunicar verbalmente ou de forma estruturada a partir de suas experiências vivenciadas. Já conhecimento tácito é aquele que o indivíduo possui a partir das experiências vivenciadas, são, portanto, pessoais.

Conhecimento tácito é um termo cunhado por Polanyi (1983) e significa aquele conhecimento que possibilita a uma pessoa resolver problemas, mas que é de difícil comunicação. Segundo o autor, pode-se saber mais do que se é capaz de expressar e nem tudo o que as pessoas sabem pode ser codificado em documentos e ferramentas, visto que as pessoas não sabem ao certo o que sabem.

Nonaka e Takeuchi (1997), ao estenderem para o campo da prática os fundamentos filosóficos do conhecimento tácito, propuseram um modelo de criação do conhecimento nas organizações estruturado em duas dimensões: ontológica e epistemológica. Na dimensão ontológica, a criação do conhecimento é entendida como um processo que amplia, em termos organizacionais, o conhecimento criado pelos indivíduos como parte da rede de conhecimentos da organização. Já na dimensão epistemológica, o conhecimento humano é expandido mediante a interação social entre conhecimento tácito e conhecimento explícito. Essa interação ficou conhecida como Modelo SECI (Socialização, Externalização, Compartilhamento e Internalização), também chamada de Espiral do Conhecimento, como mostrado na Figura 1. 
Figura 1 - Espiral do Conhecimento,

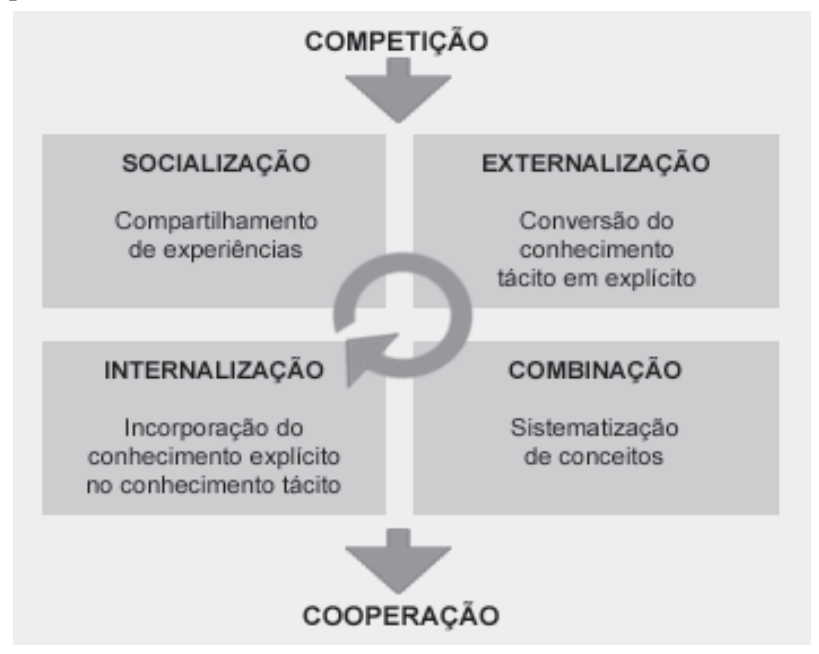

segundo Nonaka e Takeuchi (1997, p. 80)

Krogh (2001, p. 69) cunhou o termo "especialista solícito" e o definiu como “o indivíduo que atinge determinado nível de excelência pessoal, envolvendo conhecimentos tanto tácitos como explícitos, e se considera responsável pelo compartilhamento do processo." A criação de conhecimento em uma comunidade ou em uma organização que convive com diferentes tipos de conhecimento se concretiza por meio da ajuda e do compartilhamento entre seus membros.

A colaboração, por sua vez, é um elemento crítico para o sucesso das estratégias organizacionais. A colaboração deve existir entre as estruturas funcionais, entre os níveis hierárquicos e entre as fronteiras da organização (CROSS, 2004). Quanto maior a colaboração, mais estreito o relacionamento e mais próxima estará a organização de seus objetivos. Como o trabalho acontece por meio de redes colaborativas informais, que transpassam os limites físicos e hierárquicos, os gestores têm um forte desafio que é o de proporcionar um ambiente em que a colaboração seja mais efetiva.

Nas redes informais e organizacionais, a troca de informação é intensa e constante. Trata-se de ambientes onde experiências, aprendizados e dúvidas, entre 
outros aspectos pessoais e profissionais são compartilhados por meio da socialização dos conhecimentos tácitos (NONAKA; TAKEUSHI, 1997, p. 69-71). As redes formais ou informais são, neste contexto, na maioria das vezes, fontes de criação e propagação de conhecimento (ALLEE, 2003, p. 78-84).

O conceito de GC parte da premissa de que todo o conhecimento dos processos de negócio existentes "na cabeça de seus profissionais" ou "no coração de seus processos" faz parte do conhecimento organizacional de propriedade da empresa (PARADIGMA, 2008). Nesse contexto, caso os processos e os produtos oriundos deles não estejam documentados, a empresa estará permanentemente refém das pessoas que detêm esse conhecimento tácito.

Muito se fala a respeito da importância do conhecimento para atuação no mundo dos negócios, principalmente quando se trata de investimentos financeiros. Vivencia-se um cenário de rara complexidade, tanto no mundo corporativo quanto na sociedade em geral. É nesse contexto que a GC se tornou um importante recurso estratégico. É preciso lidar com informações sobre o ambiente em que se está inserindo o negócio específico, com informações oriundas das demonstrações contábeis das empresas e com a evolução de seus negócios, tanto no presente como nas prospecções de novos produtos e serviços.

Para tanto, deve-se considerar a forma da organização ao tratar sobre a GC organizacional, interna e externamente, como um dos tópicos que envolvem a governança corporativa, pois esse conhecimento é um fator fundamental no momento de estabelecer o seu valor, por exemplo, em termos de sua cotação no mercado de ações. A capacitação de seus profissionais é uma arma fundamental para o fomento dos negócios organizacionais, principalmente quando a organização atua no mercado de capitais.

A seguir falaremos a respeito de Ferramentas Tecnológicas, e serão abordados alguns estudos a respeito da gestão do conhecimento e o mercado de capitais. 


\subsection{Mercado de capitais}

A economia dos países é composta de diversos segmentos, estando, entre eles, o mercado do dinheiro. O Quadro 1 ilustra esses segmentos.

Quadro 1 - Os mercados do Dinheiro (CAVALCANTE, 2005)

\begin{tabular}{|c|c|c|c|}
\hline Segmentos & Prazos & Finalidade & $\begin{array}{c}\text { Tipo de } \\
\text { intermediação }\end{array}$ \\
\hline Monetário & $\begin{array}{l}\text { Curtíssimo, } \\
\text { curto }\end{array}$ & $\begin{array}{c}\text { Controle da liquidez } \\
\text { monetária da economia, } \\
\text { suprimentos momentâneos } \\
\text { de caixa }\end{array}$ & $\begin{array}{c}\text { Bancário e não } \\
\text { bancário }\end{array}$ \\
\hline Crédito & $\begin{array}{l}\text { Curto e } \\
\text { médio }\end{array}$ & $\begin{array}{c}\text { Financiamento do consumo } \\
\text { e capital de giro das } \\
\text { empresas }\end{array}$ & $\begin{array}{c}\text { Bancário e não } \\
\text { bancário }\end{array}$ \\
\hline Câmbio & À vista, curto & $\begin{array}{c}\text { Conversão de valores em } \\
\text { moedas estrangeiras e } \\
\text { nacional }\end{array}$ & $\begin{array}{c}\text { Bancário e auxiliar } \\
\text { (corretoras) }\end{array}$ \\
\hline Capitais & Médio, longo & $\begin{array}{c}\text { Financiamento de } \\
\text { investimentos, de giros e } \\
\text { especiais (habitação) }\end{array}$ & Não bancário \\
\hline
\end{tabular}

Segundo Pinheiro (2002), o mercado de capitais pode ser definido como sendo um conjunto de instituições que negociam com títulos e valores mobiliários, objetivando a canalização dos recursos dos agentes compradores para os agentes vendedores. Ou seja, o mercado de capitais representa um sistema de distribuição de valores mobiliários que têm o propósito de viabilizar a capitalização das empresas e dar liquidez aos títulos emitidos por elas. O surgimento do mercado de capitais ocorreu a partir do momento em que o mercado de crédito deixou de atender às necessidades da atividade produtiva, no sentido de suprir as necessidades de capital das empresas com prazos, custos e exigibilidades adequados.

Segundo Cavalcante (2005), a necessidade de estreitar o relacionamento entre as principais praças de mercado brasileiro e a procura por meios que facilitem a realização dos negócios entre as corretoras das diversas bolsas de valores, e destas entre si, levou à criação da Comissão Nacional de Bolsas de Valores - CNBV, hoje 
denominada $\mathrm{CNB}$, associação civil sem fins lucrativos responsável pelos interesses e pela integração de suas associadas, as bolsas.

As bolsas associadas à CNB são:

- Bolsa de Valores de São Paulo - Bovespa

- Bolsa de Mercadorias e Futuros - BM\&F

- Bolsa de Valores do Rio de Janeiro - BVRJ

- Bolsa de Valores de Minas, Espírito Santo e Brasília - BOVMESB

- Bolsa de Valores da Bahia, Sergipe e Alagoas - BOVESBA

- Bolsa Brasileira de Mercadorias - BBM

- Câmara de Custódia e Liquidação - CETIP

A busca dos conhecimentos obtidos com os diversos tipos de pesquisa sobre o tema mercado de ações, aliada ao conhecimento dos fundamentos a respeito dele, é essencial para decidir qual a melhor opção e qual o melhor momento para se investir nesse mercado.

Invariavelmente ocorre uma procura pelo mercado de ações por parte de investidores leigos que não têm muito conhecimento sobre o assunto, mas se interessam em investir. Assim, conhecer um pouco mais do assunto demanda uma busca por informações que lhe orientem sobre o comportamento do mercado e sobre a saúde financeira das instituições nas quais ele poderá investir.

Essa relação do investidor com o mercado, inicialmente, parece simples; entretanto, está cada vez maior e requerendo informações mais precisas e confiáveis o que, seguramente, requer ferramentas que o auxiliem de forma segura na análise de dados históricos sobre o comportamento do mercado de ações e das empresas em questão.

\subsection{Ferramentas tecnológicas}

Buscando identificar ferramentas que possam ser úteis no aprendizado de um investidor da Bolsa de Valores, foram identificados diversos trabalhos que vêm 
sendo direcionados a fatores que possam auxiliar os especialistas na compreensão desse mercado. Entre as diversas abordagens para tal problema está a utilização de técnicas de mineração de dados e inteligência artificial.

Mueller (1996) propõe um modelo preditivo baseado em redes neurais artificiais como forma de antecipação do comportamento de séries de preços de ações a partir da identificação de regularidades no comportamento dessas cotações no mercado. No texto, foram conceituados temas como: redes neurais artificiais, tópicos ligados a ações e suas implicações nas organizações, tipos de análise das cotações de ações, séries temporais e apresentadas as conclusões obtidas com o trabalho após um ciclo de 20.000 iterações, comparando valores previstos e valores reais por meio de vários gráficos.

Fang e Xu (2002) investigam a previsibilidade de lucros combinando análise técnica e previsões em séries temporais convencionais. Enquanto exploram componentes previsíveis, como funções de preços passados ou lucros, regras técnicas e série de tempo, observam a existência de diferentes aspectos de previsibilidade de mercado. Identificam períodos que tendem a lucros ou a prejuízos. Os autores aplicam sua pesquisa ao índice Dow Jones, combinando regras técnicas comerciais e previsões de série temporais. Para os autores, a previsibilidade pode ser explicada em grande parte por meio de correlações entre lucros não triviais, ou seja, não previsíveis. Prejuízos não podem ser justificados somente pelos erros de previsão que ocorrem na comercialização não síncrona, ou seja, em tempos e períodos diferentes e não contíguos.

Westerhoff (2003) estuda a efetividade de limites de preços em mercados especulativos. O autor propõe um modelo estocástico não-linear que estima a confiabilidade dos aplicadores em análise técnica e fundamental para determinar as aplicações. A dinâmica do modelo simula fatos como o aparecimento de bolhas e excesso de volatilidade. A partir desse modelo, busca-se provar que os limites de preço têm potencial para reduzir volatilidade e desvios dos fundamentos do mercado acionário. Para o autor, quanto mais os aplicadores se prestam ao comportamento de extrapolar tendências, melhores são os resultados alcançados pela adoção dos limites de preço. Nesse sentido, os limites funcionam como balizadores para os aplicadores na comercialização de ações. 
Leigh et al. (2004) utilizam a Descoberta de Conhecimento em Banco de Dados (DCBD) em um estudo de caso sobre as cotações da Bolsa de Valores de Nova York e apresentam um modelo de análise sobre variações significativas nessas cotações. O trabalho se serve de cotações no período compreendido entre 1981 a 1999. Utiliza Engenharia do Conhecimento², Data Mining ou Mineração de Dados (MD), Séries Temporais e análise de comportamento financeiro, tentando identificar padrões de comportamento para justificar a razão de variações significativas.

Vasco (2004) analisa a construção de modelos de perfil de clientes em uma instituição financeira com o objetivo de obtenção de regras que sejam úteis para avaliação de risco de crédito, utilizando o processo de DCBD e técnicas de MD. Para a geração dos modelos de perfil dos clientes, utiliza a metodologia CRISP-DM (CRoss Industry Standard Process of Data Mining) para organizar e executar as diversas atividades previstas e buscar obter os resultados com qualidade. Os resultados alcançados permitiram uma caracterização dos clientes com base no seu histórico de comportamento, além dos seus dados cadastrais.

Bohm e Wenzelburger (2004), servindo-se de técnicas estocásticas, investigam o desempenho de uma carteira de ações e sua diversidade de convicções comparando-a com diversas carteiras e fatores que influenciam os diferentes desempenhos identificados entre elas.

Paulos (2004) relata uma experiência vivenciada com aplicações realizadas com ações da empresa WorldCom, estudando as variações do mercado, baseado na análise gráfica, apresentando erros na análise de risco e uma crença não justificada na reversão de tendências de retorno dos valores das cotações a patamares compatíveis com os valores aplicados. Apresenta recomendações tais como a diversificação das aplicações em uma carteira selecionada de ações. Argumenta ainda que os investidores, quando envolvidos com a aplicação de grandes volumes financeiros, devem estar atentos ao que ocorre nas bolsas do mundo inteiro, pois existe uma

2 Engenharia do Conhecimento é a área responsável pela aquisição do conhecimento explícito e a sua integração com o conhecimento implícito. 
grande chance de que o que está acontecendo no mercado acionário em outros países venha influenciar positiva ou negativamente os demais mercados.

Paulos (2004) cita que a utilização da análise fundamentalista ${ }^{3}$ geralmente se situa no lado dos números, parecendo um tanto conflitante com a ética predominante no mercado de ações, baseada na esperança, nos sonhos, na visão e em certo romantismo com tonalidades monetárias. Salienta ainda que “[...] os fundamentos representam para os investimentos o mesmo que (de maneira estereotipada) o casamento representa para o romance; ou o que os legumes representam nas refeições apesar de saudáveis, nem sempre são empolgantes". O conhecimento do tema é fundamental e importante para qualquer investidor que queira entrar nesse mercado.

Marshall et al. (2006) apresentam os resultados de uma pesquisa sobre análise utilizando a técnica de Candlestick, da variação no comportamento de preços de mercado. Essa técnica surgiu no Japão no século XVIII para tratar oscilações na cotação do mercado do arroz, nas antigas bolsas de arroz de Osaka. O termo Candlestick (candelabro, em inglês) se deve ao fato dos elementos gráficos utilizados na representação dos preços praticados pelo mercado lembrarem velas, distribuídas sobre a área do gráfico. A análise se faz por meio da identificação de "figuras" formadas pelos “candles" (velas) em determinado ponto da tendência de mercado. A partir dessas variações, identificam-se tendências de pressão de venda ou de compra do produto.

Andersen e Somette (2005) descrevem um mecanismo que opera com sistemas complexos adaptativos e lida com a previsibilidade diária de cotações com o apoio de agentes inteligentes, transientemente desacoplado da história passada. Os autores demonstram e testam suas teorias por meio de séries temporais para predição a partir de séries reais observadas no mercado financeiro.

Segundo Fu et al. (2006), a análise técnica ou grafista é uma das principais ferramentas para a investigação do comportamento do mercado de ações. Nesse

\footnotetext{
3 A análise fundamentalista considera a situação financeira, econômica e mercadológica de uma empresa, com suas expectativas e projeções de mercado.
} 
contexto, os autores consideram necessária a identificação de padrões técnicos em relação ao comportamento do preço das ações por meio de gráficos. Ao identificar Pontos Perceptualmente Importantes (PPI) a partir do espaço temporal, séries temporais e esquemas podem ser comparados. Três tipos de distâncias para identificação dos PPI são comparados nesse trabalho: euclidiana, perpendicular e vertical. Após a identificação dos PPI, os autores introduzem uma abordagem baseada em esquemas e outra baseada em regras para casamento de padrões.

Wang e Chan (2007) buscam identificar tendências do índice Nasdaq em relação ao índice tailandês TWI (Taiwan Weighted Index). A partir desse estudo, elaboram um modelo baseado em padrões de reconhecimento dessas tendências e realizam diversas experiências para validar o modelo proposto.

Gestel et al. (2006) estuda a equidade de predição no índice de preço histórico do setor químico europeu, utilizando um modelo linear de correção de erros baseado em redes bayesianas. A partir da análise dos resultados do modelo linear, esse modelo é aplicado com sucesso fora da amostra inicial de predição.

Gradojevic (2006) desenvolveu uma nova abordagem para gerar estratégias na negociação do mercado cambial, baseada em previsões a partir de um modelo híbrido entre lógica fuzzy e RNA, gerando previsões de taxas de câmbio com um dia de antecedência. Isso permitiu a investigação da evolução de um modelo dinâmico neuro-fuzzy.

Chiarella, He e Hommes (2007) analisam estatisticamente o mercado de ações visando explicar vários fenômenos de preço, incluindo bolhas de mercado, variações abruptas e resistências de preços. Propõem um modelo dinâmico para a procura de ativos negociados no mercado financeiro, combinando análises fundamentalista e grafista.

Oliveira Jr. (2007) compara modelos lineares e redes neurais artificiais como tecnologias geradoras de previsões de valores financeiros. Para o autor, a previsão é um meio importante de informação para subsidiar a tomada de decisões, visando atingir os objetivos pretendidos. Essa meta é fundamental, principalmente nas 
organizações, devido à necessidade de tomada de decisões relevantes e confiáveis. Seu modelo pretende reduzir os riscos de liquidez da instituição financeira e melhorar os lucros pela antecipação de operações de compra e venda de títulos no mercado interbancário.

Amoroso (2009) utiliza a ferramenta de mineração de dados para identificar padrões de comportamento em uma série histórica de 10 anos, envolvendo cotações de 6 empresas consideradas de primeira linha na Bolsa de Valores de São Paulo. No trabalho, foi utilizada a metodologia CRISP-DM (CRoss Industry Standard Process of Data Mining) para construir, organizar e executar o modelo e suas diversas atividades previstas.

Com a utilização de ferramentas tecnológicas, é possível obter informações que, se analisadas pelo homem, à primeira vista, não são facilmente interpretadas pelo raciocínio humano, às vezes pela complexidade dos dados, às vezes pelo grande volume de informações apresentadas. Esses conhecimentos podem ser utilizados de forma complementar aos obtidos por meio de outros canais tais como redes formais ou informais ou de experiências vivenciadas pelo investidor do mercado de capitais.

\section{Investidores}

A utilização de recursos computacionais como fator de auxílio na geração de conhecimento é cada vez mais frequente, muitas vezes não perceptível por quem a utiliza, mas ela é real.

Segundo Levy (2008), a interiorização das tecnologias intelectuais pode ser muito forte, de forma intuitiva, quase um reflexo, como pode ser o conhecimento utilizado em uma linguagem natural utilizada pelo ser humano.

O processo de metamorfose sociotécnica era lento na maior parte da sociedade, , entretanto, o seu ritmo acelerou-se nas últimas décadas, primeiro no Ocidente, explanando-se com os anos por todo o planeta. A utilização dos recursos informacionais deixou de ser um luxo e passou a ser uma necessidade para quase 
toda a comunidade. Na maioria das vezes, quando não contamos com uma rede na internet, é que se observa e se pensa em como seria difícil se ela não existisse.

O mercado de capitais está em constante transformação, portanto, a agregação de ferramentas tecnológicas e informações atualizadas são fatores fundamentais na vida de um investidor da bolsa de valores.

Agregado a isso, o investidor tem em suas mãos as diversas pesquisas que são realizadas no mundo a respeito do comportamento desses mercados e que também são fatores que complementam todo o conhecimento que um investidor deve ter no momento de se aventurar nesse mercado, que é ao mesmo tempo arriscado e desafiante.

\section{Conclusões}

O mercado acionário é movido por lucros financeiros dos investidores. Esse mercado é composto de um conjunto complexo de fatores que influenciam a evolução dos valores das cotações diárias. Em algumas situações, podem ser identificadas empresas que estejam enfrentando problemas de mercado, influenciando o valor de suas cotações, podendo gerar perdas financeiras ao investidor e, consequentemente, levá-lo a procurar novos tipos de aplicações ou a buscar ações de outras empresas, visando gerar ganhos financeiros.

A atuação do analista de mercado nesse contexto necessita de um conhecimento que transcenda aquele adquirido por meio do ensino formal. O aprendizado formal pode e deve ser complementado com o aprendizado cognitivo vivenciado pelo analista no seu dia a dia ou por meio de simulações sobre o tema (LÉVY, 2007) realizadas com o auxílio de ferramentas tecnológicas.

Nesse sentido, as séries temporais e a mineração de dados históricos podem identificar tendências e realizar predições de valores futuros. As predições podem ser comparadas com valores reais, permitindo aperfeiçoar os modelos trabalhados e melhorar os resultados em predições de séries futuras. 
O presente artigo buscou evidenciar que existem diversas linhas de estudo sobre o mercado de ações e a importância que essas pesquisas trazem na melhoria do conhecimento do acionista a respeito desse mercado.

As pesquisas mostram a utilização de identificação de perfil específico de grupos de ações, utilização da técnica de "candlestick" e previsões, utilizando a lógica fuzzi, RNA e predição de cotações de ações, utilizando mineração de dados com dados históricos, entre outros.

Os diversos métodos apresentados podem ser adotados para a análise dos preços de cotação de ações, mas vale ressaltar que, muito mais importante do que a forma de análise da variação de preços, está um fator difícil de ser mensurado: o humor e a vontade do investidor em sair ou permanecer no mercado. Esse fator dificilmente poderá ser representado em qualquer modelo que for criado para previsão da cotação de ações no mercado.

\section{The use of technological tools as a way of learning for the investor in the stock market}

\section{Abstract}

The financial market offers many challenges for operators and investors.

It is increasingly composed of complex devices and mechanisms, that often defy the behavior and knowledge of the humans.

The experience and the learning tools are crucial to set bounds for investments on capital market.

Part of it takes care of the stock market, which in seconds can represent significant losses for the investors.

Many investigations have been performed using models and technological tools, involving mainly data mining, to aggregate knowledge for those who serve this market. 
This article aims to introduce some of these researches, serving as a north to the professionals who deal with the stock market, and permitting greater visibility for all who are interested on this matter.

Keywords: Business Intelligence. Business Performance Management. Management Performance Control.

\section{Referências}

ALLEE, V. The future of knowledge: increasing prosperity through value networks. Burlington: Butterworth-Heinemann, 2003.

AMOROSO, E. D. Um estudo de caso sobre mineração de dados como instrumento de aprendizagem para o investidor do mercado de ações. 2009. Dissertação de (Mestrado em Gestão do conhecimento e tecnologia da informação) - Universidade Católica de Brasília-UCB, Brasilia, 2009.

ANDERSEN, J. V.; SORNETTE, D. A mechanism for pockets of predictability in complex adaptive systems. Europhys. Lett., [S.1.], v. 70, n. 5, p. 697-703, 2005.

BOHM, V.; Wenzelburger, J. On the performance of efficient portfolios. J. Econ. Dyn. Control., [S.1.], v. 29, n. 4, p. 721-740, 2005.

CAVALCANTE, F; MISUMI, J. Y.; RUDGE, L. F. Mercado de capitais: o que é e como funciona. Rio de Janeiro: Elsevier, 2005.

CAVALCANTI, M.; GOMES, E. A nova riqueza das organizações: os capitais do conhecimento. Revista TN Petróleo, [S.1.], v. 3, n. 16, p. 1-10, 2000.

CHIARELlA, C.; HE, X.; HOMMES, C. H. A dynamic analysis of moving average rules. Tinbergen Institute. Discussion Paper No. TI 05-057/1. May, 2005. Journal of Economic Dynamics and Control, v. 30, n. 9-10, p. 1729-1753, set./out. 2006.

CRISP-DM. CRISP-DM 1.0: Step-by-step data mining guide. Disponível em $<$ http://www.crisp-dm.org>. Acesso em: 11 nov. 2008. 
CROSS, R.; PARKER, A. The hidden of social networks: understanding how work really gets done in organizations. Boston: Harvard Business School, 2004.

DRUCKER, P. Post-capitalist society. Oxford: Butterworth-Heinemann, 1993.

FANG, Y.; XU, D. The predictability of asset returns: an approach combining technical analysis and time series forecasts. Int. J. Forecast., [S.1.], v. 19, n. 3, p. 369-385, 2003.

FU, T.-C.; CHUNG, F.-L. et al. Stock time series pattern matching: template-based vs. rule-based approaches. Eng. Appl. Artif. Intell., [S.1.], v. 20, n. 3, p. 347-364, 2007.

GESTEL, T. et al. A Bayesian nonlinear support vector machine error correction model. J. Forecast., [S.1.], v. 25, n. 2, p. 77-100, 2006.

GRADOJEVIC, N. Non-linear, hybrid exchange rate modeling and trading profitability in the foreign exchange market. J. Econ. Dyn. Control., [S.1.], v. 31, n. 2, p. 557-574, 2007.

KROGH, Georg Von. Solicitude nas Organizações. In: . Facilitando a criação de conhecimento: reinventando a empresa com o poder da inovação contínua. Rio de Janeiro: Campus, 2001. cap. 3.

LEIGH, W.; MODANI, N.; Hightower, R. A computational implementation of stock charting: abrupt volume increase as signal for movement in New York Stock Exchange composite index. Decis. Support Syst., [S.1.], v. 37, n. 4, 2004.

LEVY, Pierre. As tecnologias da inteligência: o futuro do pensamento na era da informática. Rio de Janeiro: Editora 34, 2008.

MARSHALL, B. R.; YOUNG, M. R.; ROSE, L. C. Candlestick technical trading strategies: Can they create value for investors? J. Bank. Financ., [S.1.], v. 30, n. 8, p. 2303-2323, 2006.

MUELLER, A. Uma aplicação de redes neurais artificiais na previsão do mercado acionário. 1996. Dissertação (Mestrado em Engenharia de Produção)-Universidade Federal de Santa Catarina, Florianópolis, 1996.

NONAKA, I.; TAKEUCHI, H. Criação de conhecimento na empresa. Rio de Janeiro: Campus, 1997.

OLIVEIRA JR., Waldomiro. Estudo comparativo entre modelos lineares e redes neurais artificiais como tecnologias geradoras de expectativas e previsões de 
valores financeiros. 2007. Dissertação (Mestrado em Gestão do Conhecimento e da Tecnologia da Informação)-Universidade Católica de Brasília, Brasília, 2007.

PARADIGMA. A gestão do conhecimento na prática. Disponível em: $<$ http://www. paradigma.com.br/gestao-do-conhecimento-na-pratica/view $>$. Acesso em: 18 ago. 2008. Também publicado na Revista HSM Management, n. 42, 2004.

PAULOS, J. A. A lógica do mercado de ações: uma análise prática do mercado de ações. Tradução de Afonso Celso da Cunha Serra. Rio de Janeiro: Elsevier, 2004.

PINHEIRO, J. L. Mercado de capitais: fundamentos e técnicas. 2. ed. São Paulo: Atlas, 2002.

POLANYI, M. The tacit dimension. Gloucester: Peter Smith, 1983.

WANG, J.; CHAN, S. Stock market trading rule discovery using pattern recognition and technical analysis. Expert Syst. Appl., [S.1.], v. 33, n. 2, p. 304-315, 2007.

WESTERHOFF, F. Speculative markets and the effectiveness of price limits. J. Econ. Dyn. Control., [S.1.], v. 28, n. 3, p. 493-508, 2003. 


\section{Para publicar na revista Universitas Gestão e TI, entre no endereço eletrônico www.publicacoesacademicas.uniceub.br. Observe as normas de publicação, facilitando e agilizando o trabalho de edição.}

